\title{
The effectiveness of waste oyster shells (WOS) as major fine aggregate replacement in concrete
}

\author{
Xinglu Cai ${ }^{1,2}$, Ruiwen Liu ${ }^{1}$, Junhao Fan ${ }^{1}$, and Yingdi Liao ${ }^{1, *}$ \\ ${ }^{1}$ College of Harbour, Coastal and Offshore Engineering, Hohai University, Nanjing 210098, China \\ ${ }^{2}$ Materials \& Structural Engineering Department, Nanjing Hydraulic Research Institute, Nanjing 210029, China
}

\begin{abstract}
Over-exploitation of natural river sand and waste oyster shells (WOS) dumped randomly will cause serious environmental issues. Thus, a drive to using crushed WOS as fine aggregates to substitute river sand in concrete production has been initiated. This paper conducted experimental research to study the possibility of employing the crushed WOS as $100 \%$ fine aggregates in concrete. The workability, compressive strength and its size-effect, and sustainability performance of the concrete mixtures were investigated. The results indicated that, under the same water-cement ratio, the WOS concrete showed a great improvement in strength properties while a decline was found in slump tests, compared to the control concrete. Besides, the use of the crushed WOS in concrete production resulted in a modification in both eco-efficiency and cost-efficiency.
\end{abstract}

\section{Introduction}

With the developments of the society, mostly in construction industry, there is a huge growth in the demand for sand in many countries including China. However, sand mining is an age-old practice to extract sand, mainly from riverbeds and open pits. This may cause many environmental problems such as negative impacts on the depth of the riverbed, the water table, and salt content of the rivers etc., associated with it. Therefore, people try to find alternatives to natural river sand to produce concrete. Several studies have demonstrated that the WOS are composed of $\mathrm{CaCO}_{3}$ (more than 95\%), which will not react with binder materials [1]. Currently, shell production exceeds 10 million tons in china every year. Most of these WOS are abandoned randomly in the open air, occupying land resource and producing unpleasant odors and flies. Finally, this may cause serious health and environmental problems for humans. Thus, using crushed WOS as substitution materials for river sand to produce the WOS concrete may solve the environmental issues resulting from waste materials and over-exploitation of river sand very well.

Although there has been much research upon the WOS concrete, which mainly focused on the possibility of utilization the crushed WOS as alternative aggregates in cementitious materials [2-4]. For example, scholars have explored the influence of crushed WOS aggregate particle size on the mechanical and durable performance of materials [3]. However, most of the research directly used the mix ratio of ordinary concrete, without considering the influence of factors such as watercement ratio, cementing material dosage, and sand ratio.
At the same time, most studies about the WOS mortar or concrete only used the crushed WOS as part of the aggregates instead of using it as $100 \%$ fine aggregates $[5$, $6]$.

The motivation of this experimental research was to investigate the possibility of using the crushed WOS as $100 \%$ fine aggregates in concrete. The influence of the water-cement ratio, cementing material dosage, and sand ratio on the strength and slump properties of the WOS concrete was studied. Eco-efficiency and cost-efficiency analysis was also carried out to study the sustainability performance of the WOS concrete. Besides, cube specimens of different sizes were used in the experiment to investigate the influence on compressive strength sizeeffect due to the addition of the WOS fine aggregates. This study provided a further understanding of the WOS concrete, which will be beneficial to environment protection and promote the practical engineering application of this material.

\section{Experimental work}

\subsection{Raw materials}

In this study, Ordinary Portland cement (P.O. 42.5) produced by Jinan Shanshui Cement Company was employed. The density and specific surface area of the cement were $3.13 \mathrm{~g} / \mathrm{cm}^{3}$ and $3630 \mathrm{~cm}^{2} / \mathrm{g}$, separately. The compressive strength of the cement at $28 \mathrm{~d}$ is about 49.8 $\mathrm{MPa}$.

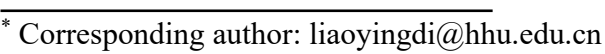




\subsubsection{Fine and coarse aggregates}

Natural river sand with a maximum particle size of $5 \mathrm{~mm}$ and a fineness modulus of 2.81 was used as one kinds of fine aggregates in the concrete mixtures.

In addition, crushed WOS were used as another kind of the fine aggregates in the concrete mixtures to replace $100 \%$ of natural river sand. The WOS fine aggregates were cleaned first to remove residual surface materials (e.g. organic matter, salt content, etc.). Then, they were put into an electric oven to dry at $100-110^{\circ} \mathrm{C}$ for $24 \mathrm{~h}$. After that, the cleaned WOS were crushed into two particle sizes, with a particle size of 1-2mm [Fig.1 (a)] and 2-4 mm [Fig.1 (b)], respectively. Finally, two particle sizes of crushed WOS were mixed in proportion to obtain the mixed WOS fine aggregates [Fig. 1 (c)] which have a fineness modulus similar to that of the natural river sand. As presented in Fig. 2, the particle size distributions of the WOS fine aggregates after mixing are compared with that of the raw materials before mixing.

Crushed stone aggregates of maximum size $20 \mathrm{~mm}$ were used as coarse aggregates.

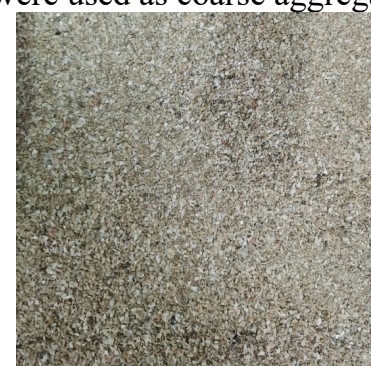

(a) 1-2 $\mathrm{mm}$

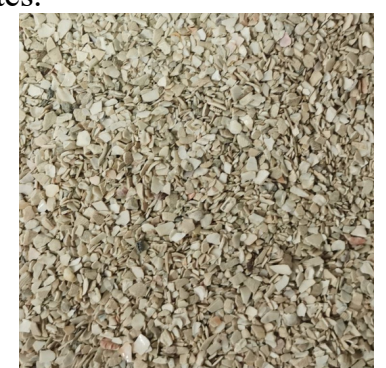

(b) $2-4 \mathrm{~mm}$

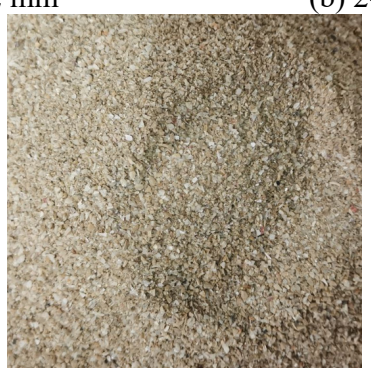

(c) after mixing

Fig. 1. Crushed WOS aggregates before and after mixing.

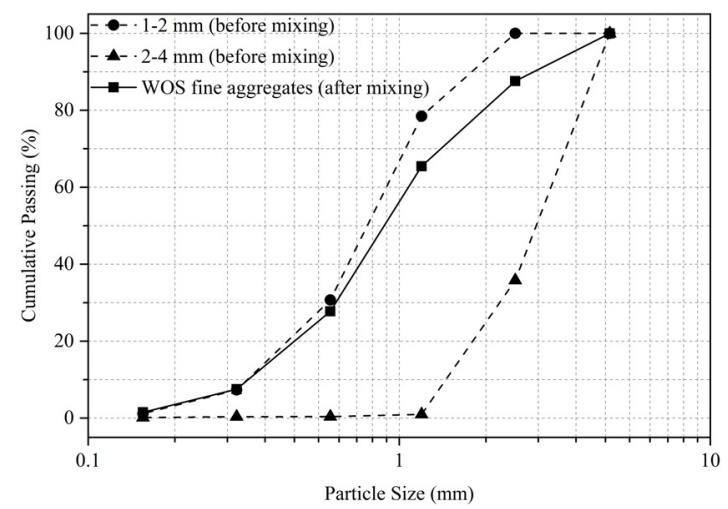

Fig. 2. Particle size distributions of crushed WOS aggregates before and after mixing.

\subsubsection{Superplasticizer}

To ensure a high workability of all mixtures, sulfonated naphthalene formaldehyde (SNF) superplasticizer with $0.5 \%$ sodium sulfate was used in the study.

\subsection{Mix proportions}

As shown in Table 1, a total of 4 mix proportions with different ingredients were designed for the concrete mixtures. The letter ' $S$ ' and ' $\mathrm{W}$ ' represent for the mixtures with river sand and crushed WOS as $100 \%$ fine aggregates, separately. S40 mix was the control concrete made with river sand as $100 \%$ fine aggregates while the other 3 mixes (W mixes) consist of different $\mathrm{w} / \mathrm{C}$ or crushed WOS content. In all mixes, the amount of the gravel and cement were kept constant. For comparison, the concrete mixtures were made with a consistent gravel and admixture content. Because the amount of coarse aggregate and admixture has a great influence on the performance of concrete $[7,8]$. The amount of admixture used (conventional SNF superplasticizer) for all mixtures was $1.8 \%$ of the cement weight.

Table 1. Mix proportions of concrete $\left(\mathrm{kg} / \mathrm{m}^{3}\right)$.

\begin{tabular}{ccccccc}
\hline Mix & w/c & Water & Cement & WOS & Sand & Gravel \\
\hline S40 & 0.40 & 200 & 500 & $/$ & 700 & 1000 \\
W35 & 0.35 & 160 & 457 & 640 & $/$ & 1000 \\
W40 & 0.40 & 200 & 500 & 700 & $/$ & 1000 \\
W45 & 0.45 & 246.6 & 548 & 754 & $/$ & 1000 \\
\hline
\end{tabular}

\subsection{Specimens casting and curing}

The concrete specimens were cast at a room temperature of $20^{\circ} \mathrm{C}$ in accordance with a standard [9]. To get a full mix, both fine aggregates (river sand or crushed WOS) and coarse aggregates were dry mixed in a laboratory mixer for $1 \mathrm{~min}$ before the addition of the cement which was further mixed for $1 \mathrm{~min}$. Then, water containing fully dissolved superplasticizers was added for mixing more than $2 \mathrm{~min}$. At last, the concrete specimens were cast in different molds which had been oiled before concreting. In order to achieve proper compaction of concrete, the casting of concrete was done in three layers.

After casting, all the concrete specimens were covered with plastic sheets before being air-cured in the laboratory at room temperature. The specimens were demoulded after $24 \mathrm{~h}$ and water cured in a standard water curing tank (temperature ranging from $20-26^{\circ} \mathrm{C}$ ) until the age of testing.

\subsection{Testing}

\subsubsection{Slump test}

As normal procedure on concrete material study, the slump test was carried out to test the workability of concrete, before casting the specimens, in accordance with SL352-2006 [10]. The mold for the slump test measures top diameter of $100 \mathrm{~mm}$, while the larger 
opening at the base was $200 \mathrm{~mm}$ and $300 \mathrm{~mm}$ in height. The slump cone was filled in three layers, tamping each layer 25 times with a $16 \mathrm{~mm}$ diameter rod to avoid voids. The top surface of the concrete was leveled off. Then, with the cone removed, the height of the slump of fresh concrete was measured.

\subsubsection{Compressive strength test}

Among various strengths of concrete, compressive strength has received a large amount of attention, because the concrete is primarily meant to withstand compressive stress. Compressive strength test was executed according to the SL352-2006 [10] by using an automatic compression testing machine with a maximum capacity of $2000 \mathrm{kN}$. The load is applied gradually, till the failure for the specimen. To deduce the size-effect coefficients for the compressive strength of the concrete, four groups of cubic specimens with side lengths of 100 and $150 \mathrm{~mm}$ were carefully prepared based on mix proportions. Three specimens were tested for each group at $28 \mathrm{~d}$.

\subsubsection{Sustainability performance analysis}

Both river sand and crushed WOS can be used as fine aggregates for the preparation of concrete. However, the production of natural river sand releases amount of carbon dioxide $\left(\mathrm{CO}_{2}\right)$ and this results in the emission of large amount of greenhouse gases. The mining of river sand is restricted in many countries including China due to ecological issues [11], causing the price of river sand to rise. A sustainability evaluation was carried out to assess the effect of WOS aggregates on both the environmental impact and material cost (environmental and economic objectives) of concrete mixtures with different mix proportions.

\section{Results and discussions}

\subsection{Workability}

Table 2. Slump test for fresh concrete.

\begin{tabular}{clc}
\hline Class & \multicolumn{1}{c}{ Slump } & Rating \\
\hline S40 & $>210 \mathrm{~mm}$ & Excellent \\
W35 & $<10 \mathrm{~mm}$ & Bad \\
W40 & $140 \sim 160 \mathrm{~mm}$ & General \\
W45 & $>210 \mathrm{~mm}$ & Excellent \\
\hline
\end{tabular}

To measure the workability of fresh concrete, slump tests were conducted. Table 2 showed the results of the slump test for all concretes. The S40 group and the W40 group had the same water-cement ratio, cement dosage and sand ratio. However, S40 and W40 concrete gave a true slump value of more than $210 \mathrm{~mm}$ and ranging from 140 to $160 \mathrm{~mm}$, respectively. The results of these two groups showed that when using crushed WOS to replace $100 \%$ of river sand as fine aggregates to produce concrete, will adversely affect the workability of the concrete. This was caused by the defects of the shell material itself compared with river sand. A large specific surface and a large amount of internal porosity of the crushed WOS increases the amount of surface-adsorbed water when mixing [4]. For the 'W' series, the difference in sand rate between the groups was exceedingly small. With the increase of the water-cement ratio and the amount of cement, the slump of the mixture gradually increases.

\subsection{Compressive strength and its size-effect}

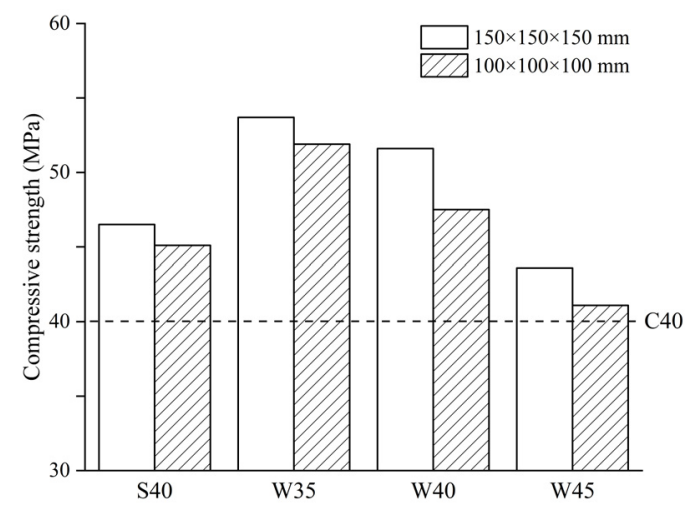

Fig. 3. Strength of specimens with different sizes (28 d).

S40 group was the control group, which was designed in accordance with the C40-marked concrete. The WOS concrete was based on the control group, adjusting the water-cement ratio, the amount of cementitious material and the sand rate parameters. To explore the compressive strength of WOS concrete and its sizeeffect, the results of compressive strength of specimens with different sizes at $28 \mathrm{~d}$ are shown in Fig. 3. The compressive strength of all concrete reached $40 \mathrm{MPa}$ at $28 \mathrm{~d}$. However, the compressive strength of the WOS concrete was affected by the added WOS fine aggregates. When comparing the W40 concrete with the S40 concrete, the compressive strength increased with the addition of the crushed WOS. This increase may also be attributed to the poor surface morphology of the crushed WOS, which results in an enhancement in mechanical bond strength between the WOS aggregates and the cement. For all of the WOS concrete, the compressive strength decreased significantly as the water-cement ratio increased. This is consistent with other research conclusions on ordinary concrete [12].

Table 3. Size-effect coefficients for concrete.

\begin{tabular}{cccc}
\hline Class & $\begin{array}{c}\mathbf{1 5 0} \mathbf{~ m m} \\
(\mathrm{MPa})\end{array}$ & $\begin{array}{c}\mathbf{1 0 0} \mathbf{~ m m} \\
(\mathrm{MPa})\end{array}$ & Coefficient \\
\hline S40 & 46.5 & 45.1 & 0.97 \\
$\mathrm{~W} 35$ & 53.7 & 51.9 & 0.97 \\
$\mathrm{~W} 40$ & 51.6 & 47.5 & 0.92 \\
W45 & 43.6 & 41.1 & 0.94 \\
\hline
\end{tabular}

The results of table 3 are conducted to analyse the size-effect on the compressive strength of the WOS concrete. The compressive strength of $100 \mathrm{~mm}$ cube for 
W40 concrete increased by $8.6 \%$ compared with the same mix, but different in size of $150 \mathrm{~mm}$ cube. The ratio of the compressive strength of the WOS concrete cubes in size $100 \times 100 \times 100 \mathrm{~mm}$ to the cubes in size $150 \times 150 \times 150 \mathrm{~mm}$ was between 0.92 and 0.97 , and the average of this ratio was 0.94 .

\subsection{Sustainability performance}

\subsubsection{Eco-efficiency}

It is estimated that the total $\mathrm{CO}_{2}$ emission from the production of $1 \mathrm{t}$ natural river sand corresponds to $5.1 \mathrm{~kg}$ [11]. However, the amounts of $\mathrm{CO}_{2}$ emissions in the process of crushed WOS and mixing water were low and could be ignored. So, only $\mathrm{CO}_{2}$ emissions of cement, river sand, and coarse aggregates were considered. In this study, the eco-efficiency of the WOS concrete was determined by the $\mathrm{CO}_{2}$ emission factor, and the results are presented in Table 4. The $\mathrm{CO}_{2}$ emissions of cement and aggregates were obtained from former literatures [11].

Table 4. Total $\mathrm{CO}_{2}$ emissions of concrete $\left(\right.$ per $\left.\mathrm{m}^{3}\right)$.

\begin{tabular}{ccccc}
\hline Mix & \multicolumn{3}{c}{$\mathbf{C O}_{2}$ emission $\left(\mathbf{k g} / \mathbf{m}^{\mathbf{3}}\right)$} & Total \\
\cline { 2 - 4 } & Cement & Sand & Gravel & $\left(\mathbf{k g} / \mathbf{m}^{\mathbf{3}}\right)$ \\
\hline S40 & 383.30 & 3.57 & 4.80 & 391.67 \\
W35 & 350.34 & $/$ & 4.80 & 355.14 \\
W40 & 383.30 & $/$ & 4.80 & 388.10 \\
W45 & 420.10 & $/$ & 4.80 & 424.90 \\
\hline
\end{tabular}

As shown in Table 4, concrete with crushed WOS had a reduction in the total $\mathrm{CO}_{2}$ emissions, comparing the W40 concrete with the control concrete (S40). But for the WOS concrete with different water-cement ratios, as the amount of cement increased, $\mathrm{CO}_{2}$ emissions increased. For a given content, the WOS concrete had lower total $\mathrm{CO}_{2}$ emissions than normal concrete made with natural river sand. Utilizing crushed WOS had a higher eco-efficiency than using natural river sand during the production of concrete.

\subsubsection{Cost-efficiency}

Cost-efficiency is an important indicator to evaluate the sustainability of the concrete material. The unit prices of raw materials were obtained from former research [5], which did not include the transportation, handling, placement, and quality control costs. The results of the cost-efficiency of different concrete mixtures are shown in Table 5.

As shown in the table, the WOS concrete were more economical. The total material costs of the WOS concrete $\left(\right.$ per $\mathrm{m}^{3}$ ) were 351.69 RMB, 379.20 RMB, and 408.36 RMB. The WOS concrete were more economical than the control concrete (S40), by $18.5 \%, 12.2 \%$ and $5.4 \%$. The use of the crushed WOS as fine aggregates in concrete production resulted in an improvement in costefficiency. By comparing the total material costs of the $\mathrm{S}$ and $\mathrm{W}$ series to each other, the contribution of the type of the fine aggregate to the cost-efficiency of the concrete was greater than that of cement.

Table 5. Cost-efficiency of concrete (per $\left.\mathrm{m}^{3}\right)$.

\begin{tabular}{|c|c|c|c|c|c|c|}
\hline \multirow[t]{2}{*}{ Mix } & \multicolumn{5}{|c|}{ Raw material costs $\left(\mathrm{RMB} / \mathrm{m}^{3}\right)$} & \multirow{2}{*}{$\begin{array}{c}\text { Total } \\
\left(\mathrm{RMB} / \mathrm{m}^{3}\right)\end{array}$} \\
\hline & Water & Cement & WOS & Sand & Gravel & \\
\hline $\mathrm{S} 40$ & 0.70 & 234.50 & I & 136.50 & 60.00 & 431.70 \\
\hline W35 & 0.56 & 214.33 & 76.80 & I & 60.00 & 351.69 \\
\hline W40 & 0.70 & 234.50 & 84.00 & I & 60.00 & 379.20 \\
\hline W45 & 0.86 & 257.01 & 90.48 & I & 60.00 & 408.36 \\
\hline
\end{tabular}

\section{Conclusion}

Based on the study, it was shown that crushed WOS have great potential to be used as aggregate replacement in concrete production. Under the same water-cement ratio, the workability of the WOS concrete was consider lower compared to normal concrete with river sand as fine aggregates, but it could still meet the engineering requirements. However, the WOS concrete had better compressive strength performance and sustainability performance than normal concrete. The average ratio of the compressive strength of the WOS concrete cubes in size $150 \times 150 \times 150 \mathrm{~mm}$ to $100 \times 100 \times 100 \mathrm{~mm}$ was 0.94 .

\section{Acknowledgments}

This study was supported by the Fundamental Research Funds for the Central Universities (No. B200203193) and the Postgraduate Research \& Practice Innovation Program of Jiangsu Province (No. SJCX20_0163). These are gratefully acknowledged.

\section{References}

1. E. Yang, S. Yi, Y. Leem, Cement Concrete Res. 35, 2175 (2005)

2. G. Yoon, B. Kim, B. Kim, S. Han, Waste Manage. 23, 825 (2003)

3. S. Eo, S. Yi, Mag. Concrete Res. 67, 833 (2015)

4. R. Liu, D. Chen, X. Cai, Z. Deng, Y. Liao, J. Clean. Prod. 266, 121729 (2020)

5. D. Chen, T. Pan, X. Yu, Y. Liao, H. Zhao, Environ. Eng. Sci. 36, 1079 (2019)

6. D. Chen, P. Zhang, T. Pan, Y. Liao, H. Zhao, J. Clean. Prod. 237, 117811 (2019)

7. M. S. Meddah, S. Zitouni, S. Belâabes, Constr. Build. Mater. 24, 505 (2010)

8. A. Barbudo, J. De Brito, L. Evangelista, M. Bravo, F. Agrela, J. Clean. Prod. 59, 93 (2013)

9. Ministry of Construction of the PRC. Chinese National Standard, GB/T 50080-2016 (2016)

10. Ministry of water resources of the PRC. Chinese National Standard, SL 352-2006 (2006) 
11. B.M. Mithun, M. C. Narasimhan, J. Clean. Prod. 112, 837 (2016)

12. S. B. Singh, P. Munjal, N. Thammishetti, J. Build. Eng. 4, 94 (2015) 